\title{
Letter-position coding in random consonant arrays
}

\author{
FRANCESCA PERESSOTTI \\ University of Padua, Padua, Italy \\ and \\ JONATHAN GRAINGER \\ University of Provence, Aix-en-Provence, France
}

\begin{abstract}
The processing of letter-position information in randomly arranged consonant strings was investigated using a masked prime variant of the alphabetic decision (letter/nonletter classification) task. In Experiment 1, primes were uppercase consonant trigrams (e.g., FMH) and targets were two uppercase Xs accompanied by the target letter or a nonletter (e.g., XMX, X\%X). Response times were systematically faster when target letters were present in the prime string than when target letters were not present in the prime string. These constituent letter-priming effects were significantly stronger when the target letter appeared in the same position in the prime and target stimuli. This contrast between position-specific and position-independent priming was accentuated when subjects responded only when all the characters in the target string were letters (multiple alphabetic decision) in Experiments 2 and 3. In Experiment 4, when prime exposure duration was varied, it was found that position-specific priming develops earlier than position-independent priming. Finally, Experiment 5 ruled out a perceptual-matching interpretation of these results. An interpretation is offered in terms of position-specific and position-independent letter-detector units in an interactiveactivation framework.
\end{abstract}

The present study was undertaken to examine to what extent, and at what point in time, positional information concerning individual letters is available during the processing of random consonant arrays. This is an important question not only with respect to our understanding of how positional information is coded in general, but also with respect to the more specific problem of how individual letters are coded for position during visual word recognition. In most models of visual word recognition developed over the last 25 years (e.g., Forster, 1976; McClelland \& Rumelhart, 1981; Morton, 1969; Paap, Newsome, McDonald, \& Schvaneveldt, 1982), it has been hypothesized that the printed word is stored as an orthographic description in memory. This orthographic description is most simply stated as the ordered combination of the word's component letters (e.g., word = $\mathrm{W}+\mathrm{O}+\mathrm{R}+\mathrm{D})$.

According to the models cited above, a word is recognized when information extracted from the visual display is successfully matched to the corresponding orthographic description that is stored in memory. The simple fact that anagrams exist in a given language (e.g., BALE/ ABLE) implies that each individual letter must be accu-

The authors extend their thanks to Garvin Chastain, Seth Greenberg, Lester Krueger, and one anonymous reviewer for very helpful comments on an earlier version of this paper. Reprint requests should be addressed to F. Peressotti, Dipartimento di Psicologia dello Sviluppo e della Socializzazione, Via Beato Pellegrino 26, Padova 35137, Italy (e-mail: psico08@ipdunivx.unipd.it; grainger@idf.ext.jussieu.fr). rately coded for position for correct recognition to occur. However, the fact that there is some experimental evidence for perceptual confusion among anagrams (e.g., Chambers, 1979) would also suggest that positional information is not always precisely coded. A reasonable strategy for the word-recognition system to adopt (at least as far as English is concerned) would be to provide just enough positional information regarding the individual letters present to generally avoid such perceptual confusions. Thus, for example, using a simple threevalued code (beginning, internal, and end positions) would avoid confusion of the BALE/ABLE type, but could not cope with confusion caused by transposed internal letters (e.g., BLOT/BOLT).

More recently, several authors have opted for a contextsensitive coarse coding approach to the position-instring problem (Mozer, 1987; Seidenberg \& McClelland, 1989). In Seidenberg and McClelland's model, a letter-triple scheme is adopted in which a word such as MAKE is coded as the following set of triples: _MA, MAK, AKE, KE_, where _ denotes a word boundary. The letter triples in this model are coded as a distributed pattern of activation over a set of featural units. Thus, individual letter representations are not considered as mediating units in word perception, since featural information contacts supraletter codes directly. Such an approach clearly avoids the problems of perceptual confusion noted above.

However theoretically appealing this approach may be, it does nevertheless have serious difficulties in accom- 
modating some basic phenomena in the word-recognition literature. Humphreys, Evett, and Quinlan (1990), for example, have shown that letter-string primes facilitate the identification of target words when prime and target share common letters. However, this priming effect depends on the relative position of shared letters in the prime and target, end letters priming only end letters and middle letters priming only middle letters. Thus, for example, recognition of the target word BLACK is facilitated by the prior presentation (under very brief exposure durations and heavy pattern masking) of the prime stimulus BVK as opposed to an unrelated control, whereas the prime stimulus TBVKU produced performance comparable to that of unrelated controls. The letter triple scheme clearly cannot handle these results, since BVK will activate the triples _BV, BVK, VK_, none of which are present in the word BLACK (a bigram version of the scheme would of course work: _B, BV, VK, K_).

Further evidence against such an approach has been provided by Grainger and Jacobs (1993). Using a paradigm similar to the one adopted by Humphreys et al. (1990), these authors have shown that the positional frequencies of individual letters in a given target determines the priming efficiency of partial-word primes (e.g., TA\%LE-table). These positional letter-frequency effects by far outweighed any effects due to either bigram or trigram frequency. This is therefore further evidence for the critical role played by individual letter representations in the process of visual word recognition.

By using the alphabetic decision task, the present experiments focused on the processing that occurs at the individual letter level. However, one problem that arises when investigating the position coding of letters in printed words is that once an orthographic description in memory has been contacted by stimulus information, positional information is immediately available (assuming that the orthographic description includes positional information). In this case, the higher order code "anchors" the individual letter representations in their correct positions. Thus, any evidence for position coding in word stimuli can be interpreted either in terms of topdown feedback from word to letter representations or in terms of the bottom-up coding of letter arrays. By using random consonant arrays as stimuli, the present study attempted to determine how accurately position information is coded in letter strings where possible top-down influences are eliminated as far as possible.

\section{Direct Versus Indirect Measures of Position Coding}

It is easily demonstrated that, under tachistoscopic exposures, letter-identity information is available before subjects can accurately report target position (Butler, 1981; Estes, Allmeyer, \& Reder, 1976; Mewhort, Campbell, Marchetti, \& Campbell, 1981). As with all research of this kind, however, one cannot exclude the possibility that although position information may have been accurately coded, the information is simply not explicitly available for report. This type of problem in interpreting these results highlights the need for more indirect measures of position coding.

One task that has proved useful in this respect is the multiletter-matching task in which subjects are presented with two letter strings and are asked to make a samedifferent decision (Angiolillo-Bent \& Rips, 1982; Krueger, 1978; Proctor \& Healy, 1985; Ratcliff, 1981). Within this paradigm, position coding can be investigated by comparing judgments with letter strings where (1) both identity and position information are identical (e.g., MFB-MFB), (2) letter position varies while letter identities do not (e.g., MFB-BMF), and (3) letter identities vary (e.g., MFB-GFB). Depending on whether subjects are instructed to respond on the basis of both identity and position information or identity information alone, the correct response to the second category of stimuli is either same or different. The main finding with respect to this particular class of stimuli is that reaction time (RT) and accuracy vary systematically as a function of the degree of displacement of the letters in each string (Angiolillo-Bent \& Rips, 1982; Proctor \& Healy, 1985, 1987; Proctor, Healy, \& Van Zandt, 1991; Ratcliff, 1981). Same responses are slower and less accurate as degree of displacement increases, while different responses follow a mirror-image pattern.

Perhaps the major drawback with this paradigm is that subjects are explicitly required either to code positional information or to ignore it. In other words, the multiletter matching task can usefully test the type of position coding that is necessary in order to perform the task at hand, but may not be very informative with respect to the type of position coding that is involved in recognizing a string of letters. Thus, although the same-different matching paradigm has clearly provided valuable insights into some of the basic mechanisms of human information processing, its relation to the more specific question of how letter-position information is coded during visual word recognition may not be as transparent as one might desire. The constituent letter-priming paradigm may offer an alternative solution to the problem of providing indirect measures of letter-position coding.

\section{The Constituent Letter-Priming Paradigm}

The logic underlying the work on constituent letter priming is as follows. If individual letters are critical units subtending visual word recognition (as opposed to more holistic information-see, e.g., Johnson, 1977), letter recognition should be facilitated by the prior presentation of the target letter in a prime word (e.g., TABLE-T). In a seminal series of experiments, Greenberg (1988) and Greenberg and Vellutino (1988) did indeed find that letter identification (in both alphabetic decision and letter-naming tasks) was facilitated by the prior presentation of the target letter in a word or random consonant prime. Thus, the prior presentation of the letter B in the prime word BOAT (for $150 \mathrm{msec}$ ) facilitated recognition of the target letter $B$ presented $30 \mathrm{msec}$ later. This constituent letter-priming effect was obtained, however, only when subjects were led to expect letter 
targets. The effect disappeared when the proportion of word targets (in mixed lists of letter and word targets) was increased (Greenberg, 1988).

The strategic nature of these effects may be principally due to the fact that prime stimuli were presented with exposure durations well above recognition threshold in these experiments. This means that subjects, on recognizing successive prime-target pairs, can be aware of the prime-target relationship that is manipulated by the experimenter, and this awareness can influence subjects' performance. Such strategic effects can be minimized by severely limiting the amount of information about prime stimuli that is consciously available to subjects by reducing prime exposure duration and introducing pattern masks (e.g., Forster \& Davis, 1984). As noted by Grainger and Jacobs (1991), when primeexposure duration is decreased to around $60 \mathrm{msec}$ and accompanied by a pattern mask, the constituent letter priming effect observed in the letter-expect condition of Greenberg (1988) also disappears.

Now, since it is known that in masked priming conditions like those used by Grainger and Jacobs (1991) one observes strong facilitatory effects of identity priming with both word (Forster \& Davis, 1984; Segui \& Grainger, 1990) and letter stimuli (Jacobs \& Grainger, 1991), the absence of an effect of constituent letter priming can be taken as evidence against letter-mediated models of visual word recognition. Grainger and Jacobs (1991) demonstrated, however, that when the target letter is embedded in a string of hash marks (e.g., \#\#T\#\#) significant constituent priming effects are obtained if the position of the target letter in the target string is the same as its position in the prime string (e.g., table-

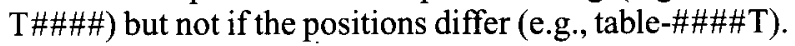

\section{The Present Study}

The present experiments represent an extension of the work of Grainger and Jacobs (1991) in a further investigation of constituent letter priming by using briefly presented masked primes. The present experiments, however, examine the processing of only random consonant arrays in an attempt to remove the possible contributions of top-down (i.e., word-letter) effects. From a methodological point of view, these experiments represent a clear improvement on previous studies in that the prime and target stimuli were presented in different-sized typographies in order to minimize the effects of purely visual (featural) prime-target overlap. Table 1 describes the different priming conditions tested in the present experiments. Experiment 1 tested position-specific and position-independent constituent priming effects with single letters as targets; Experiments 2 and 3 addressed the same issue, using multiple letter targets. Experiment 4 provided a time course analysis of these different effects, applying the logic used in recent studies of orthographic and phonological priming in visual word recognition (Ferrand \& Grainger, 1993; Perfetti \& Bell,
Table 1

Examples of the Various Priming Conditions Tested in Experiments 1-5

\begin{tabular}{|c|c|c|c|c|c|}
\hline \multirow[t]{2}{*}{$\begin{array}{l}\text { Exp. } \\
\text { No. }\end{array}$} & \multicolumn{3}{|c|}{ Prime Stimuli } & \multicolumn{2}{|c|}{$\begin{array}{c}\text { Target } \\
\text { Stimuli } \\
\end{array}$} \\
\hline & $\begin{array}{c}\text { Same } \\
\text { Positior }\end{array}$ & $\begin{array}{c}\text { Different } \\
\text { Position } \\
\end{array}$ & Absent & & \\
\hline 1 & $\begin{array}{l}\text { FRT } \\
\text { RTF }\end{array}$ & $\begin{array}{l}\text { TRF (TFR) } \\
\text { FRT (RFT) }\end{array}$ & $\begin{array}{l}\text { TRB } \\
\text { BRT }\end{array}$ & $\begin{array}{l}\text { FXX } \\
\text { XXF }\end{array}$ & $\begin{array}{l}\% X X \\
X X \%\end{array}$ \\
\hline \multirow[t]{2}{*}{$2 \& 4$} & FHK & $\mathrm{KFH}$ & NSB & FHK & TR\% \\
\hline & $1 \mathrm{st}$ & 2nd & & & \\
\hline \multirow[t]{3}{*}{3} & GRD & DGR & LZP & GDR & NF $\%$ \\
\hline & \multirow[t]{2}{*}{ Replace } & \multicolumn{2}{|l|}{ Permute } & & \\
\hline & & \multicolumn{2}{|c|}{ Positive Trials } & & \\
\hline \multirow[t]{3}{*}{5} & $\begin{array}{l}\text { FDR } \\
\text { FRS } \\
\text { RDS }\end{array}$ & $\begin{array}{l}\text { FSD } \\
\text { DFS } \\
\text { SDF }\end{array}$ & VTR & FDS & \\
\hline & \multicolumn{3}{|c|}{ Negative Trials } & & \\
\hline & $\begin{array}{l}\text { FDR } \\
\text { FRS } \\
\text { RDS }\end{array}$ & $\begin{array}{l}\text { FSD } \\
\text { DFS } \\
\text { SDF }\end{array}$ & VTR & & $\begin{array}{l}\text { FD\% } \\
\text { F\%S } \\
\% D S\end{array}$ \\
\hline
\end{tabular}

Note-The example stimuli for the different-position primes in Experiment $1 \mathrm{~B}$ are in parentheses.

1991). The demonstration of distinct time courses for the growth (and decay) of orthographic and phonological code activation in visual word recognition has provided valuable constraints with respect to providing a detailed description of the underlying mechanisms. Studying the time course of position-specific and position-independent constituent letter-priming effects should provide the same constraints with respect to an analysis of the mechanisms underlying letter-position coding. Finally, Experiment 5 tested a perceptual matching interpretation of the constituent letter-priming effect.

\section{EXPERIMENT 1}

In Experiment 1, we sought to determine whether letter-in-string identification was facilitated by the prior presentation of the target letter in a prime stimulus as compared with a control situation in which the prime stimulus did not contain the target letter. Target letters could occupy either the same position in the prime and target strings (same-position priming) or a different position (different-position priming). In addition, this experiment tested whether the amount of different position priming was a function of the degree of displacement of the critical letter between prime and target. To this end, we devised two experimental situations, one (Experiment 1A) in which the critical letter in the prime was displaced by two letter positions with respect to its position in the target string and one (Experiment 1B) in which the critical letter was displaced by only one position (see Table 1). 


\section{Method}

Subjects. Five well-trained subjects served in Experiment 1. Two of them were the authors. One subject (J.G.) was a native speaker of English, 1 was a French speaker (L.F.), and the remaining 3 (F.P., F.E.D., and R.D.A.) were native speakers of Italian. All had normal or corrected-to-normal vision.

Apparatus and viewing conditions. Stimulus presentation and timing were controlled by a Macintosh Classic computer. All stimuli were presented in a white uppercase Geneva font on a black background and were always centered on a fixation point. On each experimental trial, the subjects observed the following sequence of events. First, a fixation point, consisting of a minus sign (-), was displayed in the center of the screen and kept in view for $200 \mathrm{msec}$. Next, the prime stimulus was presented for $50 \mathrm{msec}$. It consisted of a random consonant trigram in which each letter was $0.3 \mathrm{~cm}$ wide and $0.4 \mathrm{~cm}$ high. The entire trigram was $1.01 \mathrm{~cm}$ wide. A masking pattern, consisting of a horizontal row of three "\#" signs that covered approximately the same spatial region as the prime, was then displayed for $17 \mathrm{msec}$. Finally, the target stimulus appeared and remained in view either until the subject responded or for a maximum of $800 \mathrm{msec}$. The characters of the target stimuli were twice as large as the characters of the primes. Each component character was $0.6 \mathrm{~cm}$ wide and $0.8 \mathrm{~cm}$ high. The entire target trigram was $2.21 \mathrm{~cm}$ wide. The subjects were seated at a viewing distance of approximately $50 \mathrm{~cm}$ from the computer screen.

Stimuli and Procedure. The target stimuli consisted of trigrams formed by a target letter and two Xs. Fifteen target letters were used: B, C, D, F, G, H, K, L, M, N, P, R, S, T, and V. The foil stimuli consisted of trigrams formed by a nonalphabetic sign character and two Xs. The 15 foil characters were: $\%, ?,[],,<,>, \$, \eta$, $\S, \mathfrak{c}, £, !, \Pi, \Omega$, and $\emptyset$. Both the target letters and the foil characters appeared the same number of times in either the first or the last position of the trigram, giving the two levels of the target letter-position factor. The targets were preceded by three types of prime trigrams: (1) same-position primes, which contained the target letter of the following target stimulus in the same position within the trigram (e.g., FRT-FXX); (2) different-position primes, which contained the target letter of the following target in the opposite position within the trigram (e.g., TRF-FXX) in Experiment $1 \mathrm{~A}$ and the target letter in the middle position (e.g., TFRFXX) in Experiment $1 \mathrm{~B}$; and (3) absent primes formed by consonants that were not contained in the following target stimulus.

Thus, the only difference between Experiments $1 \mathrm{~A}$ and $1 \mathrm{~B}$ lies in the degree of displacement of the different-position primes. The other two priming conditions were therefore repeated across Experiments $1 \mathrm{~A}$ and $1 \mathrm{~B}$. These conditions represent the three levels of the prime-type factor (see Table 1). The two main factors (i.e., target-letter position and prime type) were combined so that each target letter was presented three times in each position, preceded once by an absent prime, once by a same-position prime, and once by a different-position prime. The foil stimuli were preceded by the same primes as the target stimuli. Thus, there were a total of 180 trials $(3$ prime types $\times 2$ positions $\times 2$ character types $\times 15$ characters of each type $=180$ ), out of which only 90 gave RT data, given the go/no-go procedure. Each subject received 10 experimental sessions on different days, giving a total of 150 observations per experimental condition per subject in each subexperiment. Order of stimulus presentation was randomized with a different order for each experimental session.

The subjects were instructed to look at the fixation point and then to press the space bar of the keyboard as quickly as possible only if the target stimulus contained a letter (other than the two Xs which were present on every trial). If the stimulus contained a sign character, they were instructed to not respond (go/no-go instructions were used in Experiments $1-4$ in order to minimize RT variability and to improve sensitivity; see, e.g., Grice \& Reed, 1992).
RTs to target stimuli were recorded with millisecond accuracy. Subjects were tested first in Experiment $1 \mathrm{~A}$ and then in Experiment $1 \mathrm{~B}$, with several weeks separating the two.

\section{Results}

Mean RTs for each experimental condition are presented in Table 2 separately for each subject. An analysis of variance (ANOVA) was performed, with experiment (1A or 1B), target-letter position (first or last), and prime type (absent, same position, or different position) as within-subject factors.

Mean RTs were faster in Experiment 1B than in Experiment $1 \mathrm{~A}[374$ vs. $398 \mathrm{msec}$, respectively; $F(1,4)=$ $\left.13.92, M S_{\mathrm{e}}=622.39, p=.02\right]$ due to the fact that all subjects ran Experiment 1A before Experiment 1B. The effect of prime type was significant $[F(2,8)=23.88$, $\left.M S_{\mathrm{e}}=31.20, p<.001\right]$. RTs were faster in both the same- and the different-position prime conditions than in the absent condition $(381,385$, and $393 \mathrm{msec}$, respectively). Planned comparisons among these means showed that the absent condition differed significantly from both the same $[F(1,8)=46.14, p<.01]$ and the scrambled prime conditions $[F(1,8)=20.25, p<.01]$, while the difference between the two latter conditions was only marginally significant $[F(1,8)=5.25, p=$ $.051]$. The interaction between experiment and prime type was significant $\left[F(2,8)=5.06, M S_{\mathrm{e}}=5.72, p=\right.$ .038 ], reflecting the fact that net priming effects were larger in Experiment 1B than in Experiment 1A.

Mean percentages of false alarms (i.e., when subjects responded to foil stimuli) were calculated for each subject as a function of position of foil character within the trigram. The arcsine transformed data were submitted to an ANOVA with position of the foil (first and last) and experiment (1A and $1 \mathrm{~B})$ as within-subject factors. No

Table 2

Mean Reaction Times (RTs, in Milliseconds) Obtained in Experiment 1

\begin{tabular}{|c|c|c|c|c|c|c|}
\hline \multirow[b]{2}{*}{ Subject } & \multicolumn{2}{|c|}{$\begin{array}{c}\text { Same } \\
\text { Position }\end{array}$} & \multicolumn{2}{|c|}{$\begin{array}{l}\text { Different } \\
\text { Position }\end{array}$} & \multicolumn{2}{|c|}{ Absent } \\
\hline & RT & $S D$ & RT & $S D$ & $\mathrm{RT}$ & $S D$ \\
\hline \multicolumn{7}{|c|}{ Experiment $1 \mathrm{~A}$} \\
\hline J.G. & 379 & 5.9 & 379 & 8.3 & 382 & 8.3 \\
\hline F.P. & 388 & 18.6 & 394 & 16.5 & 398 & 24.7 \\
\hline L.F. & 390 & 17.0 & 391 & 23.7 & 400 & 18.9 \\
\hline F.E.D. & 429 & 44.9 & 439 & 52.5 & 446 & 43.9 \\
\hline R.D.A & 380 & 13.9 & 385 & 12.5 & 390 & 12.2 \\
\hline Mean & 393 & $20.9^{*}$ & 398 & $23.8^{*}$ & 403 & $24.3^{*}$ \\
\hline \multicolumn{7}{|c|}{ Experiment 1B } \\
\hline J.G. & 373 & 8.1 & 372 & 11.5 & 377 & 6.6 \\
\hline F.P. & 360 & 9.9 & 365 & 8.6 & 376 & 12.8 \\
\hline L.F. & 392 & 11.7 & 397 & 11.9 & 409 & 17.2 \\
\hline F.E.D. & 372 & 11.5 & 378 & 11.8 & 392 & 9.7 \\
\hline R.D.A. & 345 & 8.4 & 347 & 8.9 & 357 & 9.4 \\
\hline Mean & 368 & $17.2^{*}$ & 373 & $18.3^{*}$ & 382 & $19.2^{*}$ \\
\hline
\end{tabular}

Note-Subjects J.G. and F.P. are the authors. Standard deviations $(S D s)$ were calculated on the means of the 10 sessions participated in by each subject. * $S D$ s between subject means. 
effect was significant. The total percentages of false alarms were 3.8 in Experiment $1 \mathrm{~A}$ and 4.6 in Experiment $1 \mathrm{~B}[F(1,4)=2.16]$, and they were almost equally distributed across the two positions of the foil character in the string $(4.0 \%$ and $4.3 \%$ for the first and last position, respectively; $F<1$ ).

\section{Discussion}

The results of Experiment 1 show constituent letterpriming effects in RTs to target letters flanked by Xs. Latencies were significantly faster when the prime stimulus (a consonant trigram) contained the target letter than when it did not. Furthermore, the results provide some evidence in favor of a distinction between positionspecific and position-independent components of constituent letter priming. When the target letter occupied a position in the prime string that was different from that in the target string (e.g., TRF-FXX), significant facilitation was obtained relative to the absent condition, and the RTs tended to be longer in this position-independent priming condition than when target letters occupied the same position in the prime and target trigrams (e.g., FRT-FXX). In Experiment 2, we provide a further test of this difference between position-specific and positionindependent priming.

Moreover, a comparison of the results of the differentposition conditions of Experiments $1 \mathrm{~A}$ and $1 \mathrm{~B}$ shows that the distance (in terms of number of letters) that separates the target letter's position in the target and prime strings appears to influence the size of different-position priming. A larger different-position priming effect (relative to the absent condition) was observed in Experiment $1 \mathrm{~B}$, where the target letter was displaced by one position relative to its position in the prime string (e.g., TFR-FXX), than in Experiment 1A, where the target was displaced by two letter positions (e.g., TRF-FXX). Expressed in terms of percent priming, (absent RT present RT)/absent RT, the average effect of prime letters in the same position was $3.07 \%$ facilitation, the effect of prime letters displaced by one position was $2.62 \%$, and the effect of primes that were displaced by two positions was $1.24 \%$. However, the fact that same-position priming effects also increased from Experiment $1 \mathrm{~A}$ to $\mathrm{Ex}-$ periment $1 \mathrm{~B}$ casts some doubt on the reliability of this displacement effect.

\section{EXPERIMENT 2}

In Experiment 2, we introduced a novel variant of the alphabetic decision task specifically designed to investigate the processing of random consonant arrays. In this technique, referred to as "multiple alphabetic decision," subjects are instructed to respond only when all the characters in the array are letters. Positive targets contain three different consonants, and negative targets have two consonants and a nonletter character. Thus, to respond correctly in the multiple alphabetic decision task, sub- jects have to first be sure that all characters in the array are letters. This may not have been the case in the single alphabetic decision paradigm, since the two flanking Xs were present on every trial, and subjects may have used this knowledge in order to focus processing on the single relevant character in the string. In multiple alphabetic decision, all of the letters in the target string are critical. It is therefore hypothesized that the type of processing used to trigger a correct positive response in the multiple alphabetic decision task is a better reflection of the type of processing required to recognize a string of letters.

\section{Method}

Subjects. Three well-trained subjects (2 Italian speakers and 1 English speaker) and 1 untrained subject (Italian speaker) served in Experiment 2. Two of the well-trained subjects were the authors. All had normal or corrected-to-normal vision.

Apparatus and viewing conditions. The apparatus and viewing conditions were the same as in Experiment 1.

Stimuli and Procedure. The target stimuli were 30 trigrams formed by a random combination of the following 8 consonants, which were used in this and all following experiments: B, C, D, F, G, H, K, L, M, N, P, Q, R, S, T, V, X, and Z. In this and the following experiments, none of the target trigrams formed acronyms that were familiar to any of the subjects. The target trigrams were preceded by three types of prime: (1) same-position primes, which contained the same three letters in the same positions as in the following target; (2) different-position primes, which contained the same letters as were in the following target, but their relative positions within the trigram were altered; and (3) absent primes, which did not contain any letters that were in the following target stimulus. These conditions represent the three levels of the prime type factor (see Table 1). The foils were 30 trigrams, each of which contained two consonants and one sign character; they were preceded by the same primes as the targets with the constraint that primes and foils had no letters in common. Ten sign characters were used: $\%, ?,[],,<,>, \uparrow, !, \Pi$, and $\emptyset$. They appeared equally often at the beginning, in the middle, and at the end of the trigrams.

Three experimental blocks were constructed such that a given target was primed by a same-position prime in one block, a different-position prime in another block, and an absent prime in yet another block. Each block contained 30 targets ( 10 preceded by a same-position prime, 10 preceded by a different-position prime, and 10 preceded by an absent prime) and 30 foils preceded by the same primes as the targets. Stimulus order was randomized within each block, with a different order for each experimental session. Each subject received the three blocks in each of the six possible orderings on different days, giving a total of 180 observations per experimental condition per subject. There were three experimental conditions for the target stimuli (i.e., same-position primes, scrambled-position primes, and absent primes). No RT data were collected for the foil stimuli, given the go/no-go procedure adopted. The subjects were asked to press the space bar of the keyboard as quickly as possible if all the characters of the target stimulus were letters. They were instructed not to respond if the target stimulus contained a sign character.

\section{Results}

Mean RTs for each priming condition are presented in Table 3 separately for each subject. The data were analyzed with prime type (same position, different position, or absent) as the main factor. 
Table 3

Mean Reaction Times (RTs, in Milliseconds) Obtained in Experiment 2

\begin{tabular}{|c|c|c|c|c|c|c|}
\hline \multirow[b]{2}{*}{ Subject } & \multicolumn{2}{|c|}{$\begin{array}{c}\text { Same } \\
\text { Position }\end{array}$} & \multicolumn{2}{|c|}{$\begin{array}{c}\text { Different } \\
\text { Position }\end{array}$} & \multicolumn{2}{|c|}{ Absent } \\
\hline & RT & $S D$ & RT & $S D$ & RT & $S D$ \\
\hline J.G. & 385 & 19.5 & 397 & 16.1 & 399 & 10.2 \\
\hline F.P. & 389 & 36.3 & 418 & 37.7 & 422 & 37.9 \\
\hline F.E.D. & 390 & 17.5 & 411 & 24.3 & 419 & 17.5 \\
\hline P.D.B. & 399 & 16.9 & 411 & 24.9 & 431 & 24.5 \\
\hline Mean & 391 & $5.9^{*}$ & 409 & $8.8^{*}$ & 418 & $13.6^{*}$ \\
\hline
\end{tabular}

Note-Subjects J.G. and F.P. are the authors. Standard deviations $(S D s)$ were calculated on the means of the 18 sessions participated in by each subject. ${ }^{*} S D$ s between subject means.

There was a main effect of prime type $[F(2,6)=21.78$, $\left.M S_{\mathrm{e}}=35, p=.002\right]$. Planned comparisons among the means showed that RTs were faster in the same-position condition than in both the different-position and the absent conditions $[F(1,6)=19.56, p<.01$, and $F(1,6)=41.66$, $p<.001$, respectively]. The difference between the different-position prime condition and the absent condition was only marginally significant $[F(1,6)=4.13, p=.08]$.

As in Experiment 1, mean percentages of false alarms were calculated for each subject, depending on the position of the foil character within the trigram. The arcsine transformed data were analyzed with position of the foil (first, middle, and last) as a within-subject factor. The effect of this factor was not significant $[F(2,6)=1.32]$. Average false-alarm rates were $5.4 \%, 4.5 \%$, and $8.3 \%$ when the foil character was placed in the first, middle, and last positions of the trigram, respectively.

\section{Discussion}

In Experiment 2, a new variant of the alphabetic decision task (multiple alphabetic decision) produced robust constituent letter-priming effects. Net same-position priming effects obtained by comparing same and absent prime conditions were more than two times larger than in Experiment 1 with the single alphabetic decision task. In Experiment 2, RTs were significantly faster in the same-position prime condition than in the differentposition prime condition; in Experiment 1, this distinction between position-specific and position-independent priming failed to reach significance. Thus, it would appear that the multiple alphabetic decision task is a more sensitive tool for separating out the effects of positionspecific and position-independent constituent priming.

\section{EXPERIMENT 3}

In Experiment 2, the different-position primes differed maximally from targets with respect to letter position (e.g., KFH-FHK), with all letters occupying a different position. In Experiment 3, we examined the effects of different-position primes in which only two of three letters were displaced (e.g., FSD-FDS), thereby providing further investigation of the effects of degree of displacement of different-position primes that were examined in
Experiment 1. The tentative results of Experiment 1 led us to predict that the effect of different-position primes (relative to an absent condition) in Experiment 3 would be enhanced relative to those observed in Experiment 2, where the effects were only marginally significant. Finally, in Experiment 3, the question examined was whether the position of the unchanged letter (beginning, middle, or end) would affect constituent letter-priming effects obtained in the multiple alphabetic decision task.

\section{Method}

Subjects. The 3 well-trained subjects of Experiment 2 served in Experiment 3 along with an untrained Italian-speaker subject. All 4 had normal or corrected-to-normal vision.

Apparatus and viewing conditions. The apparatus and viewing conditions were the same as in the previous experiments.

Stimuli and Procedure. Forty randomly formed consonant trigrams served as target stimuli. They were preceded by four types of prime, all consonant trigrams: (1) first-position primes, which were derived from the targets by keeping the first letter of each target in the same position and scrambling the order of the other two; (2) middle-position primes, in which the middle letter of the target was kept constant and the first and last letters were scrambled; (3) last-position primes, in which the last letter of the target was kept constant and the first and second letters were scrambled; and (4) absent primes, which did not share any letter with the targets. These conditions represent the different levels of the prime-type factor. Forty foils were devised, as in Experiment 2, with two consonant letters and one character sign that was placed 13 times in the first, 13 times in the middle, and 14 times in the last position of the trigram. The foils were preceded by primes that were the same as those used for the targets. The target stimuli and the foils were presented four times, and four experimental blocks were constructed so that a target was presented with a different prime type in each block. Stimulus presentation order was randomized within each block, with a different order for each experimental session. Order of block presentation was counterbalanced within each subject in a Latin square design. That is, the four blocks were presented to subjects four times but in different orders and on different days, making for a total of 160 observations per experimental condition per subject. All other aspects of the procedure were the same as in Experiment 2.

\section{Results}

Mean RTs for each priming condition are presented in Table 4 separately for each subject. The data were analyzed with prime type (first letter unchanged, middle letter unchanged, last letter unchanged, or absent prime) as the main factor.

A significant main effect of prime type $[F(3,9)=$ $\left.35.61, M S_{\mathrm{e}}=9.41, p<.001\right]$ was obtained. Planned comparisons among the means confirmed that RTs were faster when the targets were preceded by first- $[F(1,3)=$ $82.8, p<.001]$, middle- $[F(1,3)=66.9, p<.001]$, or lastposition $[F(1,3)=61.38, p<.001]$ primes than when targets were preceded by absent primes. However, no significant differences were observed among the various different-position prime conditions. That is, virtually the same amount of facilitation was observed independently of which letter position was kept constant and which positions were altered.

The results of an analysis of the arcsine transformed false-alarm percentages showed no significant effect of 
Table 4

Mean Reaction Times (RTs, in Milliseconds) Obtained in Experiment 3

\begin{tabular}{|c|c|c|c|c|c|c|c|c|}
\hline \multirow[b]{2}{*}{ Subject } & \multicolumn{2}{|c|}{$1 \mathrm{st}$} & \multicolumn{2}{|c|}{ 2nd } & \multicolumn{2}{|c|}{$3 \mathrm{rd}$} & \multicolumn{2}{|c|}{ Absent } \\
\hline & RT & $S D$ & RT & $S D$ & RT & $S D$ & $\mathrm{RT}$ & $S D$ \\
\hline J.G. & 383 & 18.9 & 385 & 13.2 & 388 & 12.1 & 396 & 13.6 \\
\hline F.P. & 385 & 20.8 & 389 & 17.8 & 388 & 24.8 & 410 & 22.9 \\
\hline F.E.D. & 394 & 20.3 & 391 & 10.2 & 393 & 14.9 & 412 & 23.7 \\
\hline D.M. & 410 & 20.6 & 415 & 21.9 & 414 & 18.8 & 433 & 21.3 \\
\hline Mean & 393 & $21.3^{*}$ & 395 & $13.6^{*}$ & 396 & $12.9^{*}$ & 413 & $15.3^{*}$ \\
\hline
\end{tabular}

Note--Subjects J.G. and F.P. are the authors. Standard deviations (SDs) were calculated on the means of the 16 sessions participated in by each subject. *SDs between subject means.

position of the foil character $[3.8 \%, 4.8 \%$, and $8.6 \%$, for the first, middle, and last positions, respectively; $F(2,6)$ $=3.27]$.

\section{Discussion}

The results of Experiment 3 provide further evidence that the multiple alphabetic decision task is a useful tool for investigating constituent letter-priming effects. Strong constituent priming effects were observed when only one of the target letters occupied the same position in the prime string. These effects were independent of the position of the unchanged letter (initial, medial, or final). This particular result lends support to the hypothesis that multiple alphabetic decision (at least in the conditions of the present experiments) is performed by monitoring the activity of several letter representations in parallel. Nevertheless, as in Experiment 2, false-alarm rate varied (albeit nonsignificantly) as a function of position of the foil character in the string, with the highest error rates occurring at the last position in the string. Thus, the results obtained from positive trials appear to reflect parallel processing across all positions in the string, whereas the false-positive errors on negative trials tend to reflect a left-to-right processing bias.

An informal comparison of the results of Experiments 2 and 3 shows that the size of priming effects appeared to be influenced by the number of letter positions that remained unchanged between prime and target. Very robust effects of different-position primes were obtained in Experiment 3 , whereas the effect of different-position primes was only marginally significant in Experiment 2 . In terms of percent priming, the net facilitation obtained in the different constituent priming conditions are as follows: When all letters remained unchanged (Experiment 2, sameposition priming condition), there was $6.45 \%$ facilitation; when one letter remained unchanged (Experiment 3), there was $4.63 \%$ facilitation; and when none of the letters remained unchanged (Experiment 2 different-position priming condition), there was $2.15 \%$ facilitation.

\section{EXPERIMENT 4}

Experiment 4 provided an analysis of the time course of position-specific and position-independent priming effects obtained using the multiple alphabetic decision task. Varying prime-exposure duration in the masked priming paradigm had already provided important information relative to the time course of orthographic and phonological processing in visual word recognition (Ferrand \& Grainger, 1992, 1993, 1994; Perfetti \& Bell, 1991). Clarifying the time course of orthographic and phonological code activation in visual word recognition constrains our description of the underlying mechanisms. In Experiment 4, we applied the same logic to the distinction between position-specific and positionindependent letter-priming effects. The precise prime exposures used in this experiment were selected on the basis of Ferrand and Grainger's (1993) observation that the effects of orthographic priming are already robust with prime exposures of around $30 \mathrm{msec}$ and have practically disappeared by exposures of around $70 \mathrm{msec}$.

\section{Method}

Subjects. The 4 subjects of Experiment 2 served as subjects for this experiment.

Apparatus and viewing conditions. The apparatus and viewing conditions were the same as those used in Experiment 2, except for the prime exposure duration, which was either 33 or $67 \mathrm{msec}$.

Stimuli. The primes, the targets, and the foil stimuli were the same as in Experiment 2, with the targets being preceded by same position, different position, or absent primes. As in Experiment 2, an experimental session consisted of three blocks of stimuli in which the target and the foil stimuli were presented three times preceded by a different prime type. The stimuli were randomized before presentation, and order of block was varied within each experimental session. Each subject received 12 experimental sessions on different days, 6 with a prime duration of $33 \mathrm{msec}$ and 6 with a prime duration of $67 \mathrm{msec}$. Two of the subjects first received the $33-\mathrm{msec}$ sessions and then the 67-msec sessions; the other 2 subjects received the opposite. Otherwise, the procedure was the same as in Experiment 2.

\section{Results}

Mean RTs for each experimental condition are presented in Table 5 separately for each subject. The means were analyzed with prime type (same position, different position, and absent) and prime duration ( 33 and $67 \mathrm{msec}$ ) as within-subject factors.

There was a main effect of prime type $[F(2,6)=$ $\left.57.21, M S_{\mathrm{e}}=18.15, p<.001\right]$. RTs were faster in the same-position prime condition $(381 \mathrm{msec})$ than in the different-position prime ( $395 \mathrm{msec})$ and absent condi- 
Table 5

Mean Reaction Times (RTs, in Milliseconds) Obtained in Experiment 4

\begin{tabular}{|c|c|c|c|c|c|c|}
\hline \multirow[b]{2}{*}{ Subject } & \multicolumn{2}{|c|}{$\begin{array}{c}\text { Same } \\
\text { Position }\end{array}$} & \multicolumn{2}{|c|}{$\begin{array}{l}\text { Different } \\
\text { Position }\end{array}$} & \multicolumn{2}{|c|}{ Absent } \\
\hline & RT & $S D$ & RT & $S D$ & RT & $S D$ \\
\hline \multicolumn{7}{|c|}{ Prime Duration: $33 \mathrm{msec}$} \\
\hline J.G. & 382 & 11.2 & 394 & 15.7 & 395 & 11.5 \\
\hline F.P. & 358 & 14.2 & 376 & 21.4 & 382 & 26.7 \\
\hline F.E.D. & 386 & 14.3 & 404 & 17.9 & 412 & 15.8 \\
\hline P.D.B. & 397 & 20.4 & 422 & 18.9 & 420 & 23.1 \\
\hline Mean & 380 & $16.4^{*}$ & 399 & $19.2^{*}$ & 402 & $17.1^{*}$ \\
\hline \multicolumn{7}{|c|}{ Prime Duration: $67 \mathrm{msec}$} \\
\hline J.G. & 374 & 15.0 & 382 & 14.7 & 390 & 15.9 \\
\hline F.P. & 358 & 17.5 & 374 & 25.4 & 389 & 25.2 \\
\hline F.E.D. & 389 & 16.0 & 396 & 15.3 & 408 & 17.3 \\
\hline P.D.B. & 403 & 12.8 & 414 & 12.4 & 431 & 13.6 \\
\hline Mean & 381 & $19.4^{*}$ & 391 & $17.5^{*}$ & 405 & $19.7^{*}$ \\
\hline
\end{tabular}

Note-Subjects J.G. and F.P. are the authors. Standard deviations $(S D s)$ were calculated on the means of the 18 sessions participated in by each subject. * $S D$ s between subject means.

tion (403 msec). Planned comparisons among the means showed that all these differences were significant [same vs. different, $F(1,6)=45.53, p<.01$; same vs. absent, $F(1,6)=111.53, p<.01$; different vs. absent, $F(1,6)=$ $14.54, p<.01]$.

More interesting is the fact that the interaction between prime type and prime duration was significant $\left[F(2,6)=5.6, M S_{\mathrm{e}}=9.43, p=.042\right]$. As can be seen from Table 5 , in the two prime-duration conditions, virtually the same amount of priming was observed for same-position primes as for absent primes. However, while the means obtained with the two prime durations did not significantly differ in the same and absent prime conditions $[F(1,6)=.013$ and $F(1,6)=1.07$, respectively], the 33-msec prime duration produced significantly slower RTs than did the 67-msec prime duration in the different-position condition $[F(1,6)=11.92$, $\left.M S_{\mathrm{e}}=9.43, p=.013\right]$.

As in the previous experiments, the arcsine transformed mean percentages of false alarms were analyzed with position of the foil and prime duration as two within-subject factors. The subjects made $5.8 \%$ falsealarm responses in the $33-\mathrm{msec}$ prime-duration condition and $6.3 \%$ false-alarm responses in the $67-\mathrm{msec}$ prime-duration condition $\left[F(1,3)=11.85, M S_{\mathrm{e}}=.005\right.$, $p=.041]$. The main effect of position of the foil was also significant $\left[F(2,6)=8.13, M S_{\mathrm{e}}=.012, p=.02\right]$. Planned comparisons showed that more false-alarm responses were made when the foil was placed in the last position $(9 \%)$ than when it was placed in either the first $[F(1,6)=7.64, p=.02]$ or the middle position $[F(1,6)=15.39, p<.01]$ of the trigram $(5.3 \%$ and $3.8 \%$, respectively).

\section{Discussion}

The results of Experiment 4 clearly show that positionspecific constituent letter priming develops earlier than position-independent priming. While the former type of priming was already producing strong effects at prime exposures of $33 \mathrm{msec}$, there was no evidence for position-independent priming effects at these durations. The procedure and stimuli used in Experiment 2 were the same as those used in Experiment 4, except that the prime was exposed for $50 \mathrm{msec}$. Furthermore, since the same subjects were run in these two experiments, a more complete examination of the time course of priming can be offered by combining the results of these two experiments. Figure 1 shows the net effects (measured relative to the absent condition) of position-specific and positionindependent priming for the three prime exposures tested in Experiments 2 and 4.

From Figure 1, it is clear that position-specific priming effects vary little as a function of increasing prime exposure and appear to have already reached their maximum with 50 -msec prime exposures. On the other hand, the size of position-independent priming develops monotonically with increases in prime-exposure duration. These distinct time courses provide a high degree of constraint with respect to possible explanations of the constituent letter-priming effects observed in the present experiments. These different explanations will be presented in the general discussion.

The fact that significantly more false alarms occurred when character foils were placed at the end position in the string rather than at either the initial or medial position confirms the trend observed in Experiments 2 and 3 . Since this result suggests some form of left-to-right processing bias in the multiple alphabetic decision task, it would appear to contradict the observation that the po-

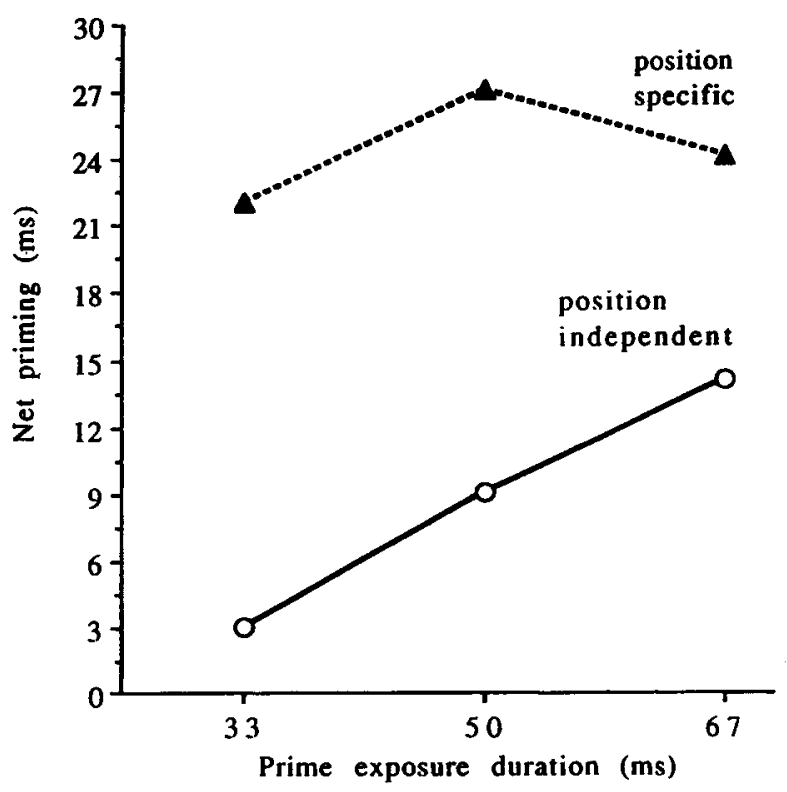

Figure 1. Net position-specific and position-independent priming effects in milliseconds, measured relative to the absent condition, obtained in Experiment 2 (50-msec prime duration) and in Experiment 4 (33- and 67-msec prime durations). 
sition of the displaced letter had no influence on the different-position priming effects in Experiment 3. This point will be analyzed more fully in the general discussion within the framework of a tentative model of the multiple alphabetic decision task.

\section{EXPERIMENT 5}

Before possible interpretations of the pattern of data obtained in the present experiments are presented, there is one possible confound that requires dismissal. The primed multiple alphabetic decision task is similar in many respects to the sequential presentation variant (as opposed to simultaneous presentation) of the multiletter matching task. Indeed, it is possible that subjects in the primed multiple alphabetic decision task were able to speed their responses in detecting a (partial) match between prime and target stimuli (i.e., a certain number of shared letters), since no such matches occurred on negative trials. ${ }^{1}$ Moreover, since perceptual matching studies have shown that RTs are faster when letter identities and positions match than when only identities match (Angiolillo-Bent \& Rips, 1982; Proctor \& Healy, 1985, 1987; Proctor et al., 1991), this could account for the difference between position-specific and positionindependent priming observed in the present experiments.

To rule out this possible interpretation of the present results, the stimuli of Experiment 5 were selected to have similar levels of match overlap between prime and target in both positive and negative trials. Moreover, a binary (yes/no) decision task was used in order to provide information about priming effects on negative trials. If detection of a (partial) match between prime and target stimuli biases subjects to make a fast positive response, then the same bias should produce higher false positive error rates when the foil stimuli have matching primes. Thus, the main goal of Experiment 5 was to test for constituent letter-priming effects on positive trials (as obtained in the previous experiments) while checking for the effects of prime-target letter matches on negative trials.

As indicated in Table 1, two types of priming on positive trials were examined in Experiment 5: (1) a replace condition, where the prime stimulus shares two of the target's letters in the correct position (e.g., FDR-FDS); and (2) a permute condition, where all three target letters appear in the prime stimulus, one in the correct position and the remaining two in different positions (e.g., FSDFDS). When compared with a condition where the prime stimulus contains none of the target letters (absent condition), one can, on the basis of the results of Experiments 2 and 3 , make the following predictions. The permute condition is identical to that tested in Experiment 3 , which yielded an average $4.6 \%$ facilitation effect. The replace condition can be roughly considered as two-thirds of the same-position condition tested in Experiment 2 , which produced a $6.5 \%$ facilitation effect. This would lead us to predict almost equivalent priming effects ( $4.6 \%$ and $4.3 \%$, respectively) in the permute and replace priming conditions tested in Experiment 5.

\section{Method}

Subjects. Seven students at the University of Padova and 1 of the authors (F.P.) served as subjects in this experiment. All were Italian speakers, and all had normal or corrected-to-normal vision.

Apparatus and viewing conditions. The apparatus and viewing conditions were the same as those in the previous experiments. Prime exposure duration was set at $50 \mathrm{msec}$.

Stimuli and Procedure. The positive target stimuli were 60 trigrams formed by three different consonants (none of which were familiar acronyms for the subjects tested in the experiment). They were preceded by three types of prime: (1) Replace primes, which were formed by two of the target letters in the same position plus a different letter. The different letter could be placed in the initial position (e.g., RDS-FDS), in the middle position (FRS-FDS), or in the last position of the trigram (FDR-FDS). (2) Permute primes, which were formed by the same letters as the target but arranged in such a way that only one of the letters was in the same position, as in Experiment 3. One-third of the permute primes had the initial letter of the trigram in the same position as in the target (e.g., FSD-FDS), one-third had the middle letter in the same position as in the target (SDF-FDS ), and one-third had the last letter in the same position as in the target (DFS-FDS). (3) Absent primes, which were formed by three letters not contained in the target (e.g. VTR-FDS). Each positive target was presented nine times, preceded by three permute primes, three replace primes (i.e., one for each position), and three absent primes (three absent primes were necessary in order to have the same number of trials in the absent condition as in the permute and replace conditions, and also to equate the total number of positive and negative trials).

The negative targets consisted of trigrams formed by 2 consonants and 1 of the 15 keyboard signs used in Experiment 1. From each positive target trigram, three negative targets were derived in such a way that the first, the second, or the third letter of the trigram was replaced by a sign character (e.g., FDS $\rightarrow$ FD $\%, F \%$, $\% \mathrm{DS}$ ). The same negative target stimulus was presented three times: preceded by a replace prime (e.g., FDR-FD\%); a permute prime, where one letter maintained the same position and another letter was displaced (FSD-FD\%); and an absent prime (VTRFD\%). Note that the same set of prime stimuli served for both positive and negative targets (see Table 1).

The 60 target trigrams were randomly assigned to four blocks (to avoid fatigue), each containing 15 positive target trigrams and the corresponding 45 negative targets. Since, as noted above, each positive target was presented 9 times and each negative target 3 times, every block contained an equal number (135) of positive and negative trials. Each subject received the four blocks in the order of a counterbalanced Latin-square design on different days, giving a total of 180 observations per prime condition per subject ( 60 for each of the three positions tested). The subjects had two response keys, one for positive responses (when the target trigram was formed entirely by letters) and one for negative responses (when the target trigram contained a nonalphabetic sign). The leftmost and the rightmost keys of the keyboard were selected as response buttons. Response side was counterbalanced within each subject on successive blocks.

\section{Results}

Table 6 provides the mean RTs on positive and negative trials for each prime condition, averaged over subjects. An analysis was performed on the RTs for correct responses, with response type (positive or negative) and prime type (replace, permute, absent) as within-subject 
factors. Positive responses were $34 \mathrm{msec}$ faster than negative responses $\left[F(1,7)=143.58, M S_{\mathrm{e}}=95.9, p<\right.$ $.001]$, and there was a marginally significant main effect of prime type $\left[F(2,14)=3.69, M S_{\mathrm{e}}=29.68, p=\right.$ $.052]$. The interaction between these two factors was also marginally significant $\left[F(2,14)=3.34, M S_{\mathrm{e}}=\right.$ $36.25, p=.056]$. Nevertheless, as is clear from Table 6 , when analyzed separately on positive and negative responses, the effects of priming were significant only in the former $\left[F(2,14)=7.35, M S_{\mathrm{e}}=32.09, p<.01\right]$. Table 6 shows that RTs to correct negative responses were absolutely flat across the different priming conditions. Planned comparisons between the means showed that, for correct positive responses, both the replace condition and the permute condition gave significantly faster RTs than the absent condition $[F(1,14)=12.46$, $p<.01$, and $F(1,14)=9.27, p<.01$, respectively]. Removing F.P.'s data from this analysis did not alter the general pattern of effects.

An analysis of the arcsine transformed error percentages with response type (positive or negative) and prime type (replace, permute, absent) as within-subject factors showed a significant main effect of response type. There were fewer false negative errors (responding no when yes was correct) than false positive errors (responding yes when $n o$ was correct) $\left[F(1,7)=9.07, M S_{\mathrm{e}}=.001\right.$, $p=.02]$. No other main or interaction effect was significant. Two separate analyses performed on the data for negative and positive trials showed marginally significant priming effects for false negative errors $[F(2,14)=$ $\left.3.58, M S_{\mathrm{e}}=.007, p=.055\right]$, but not for false positive errors $[F(2,14)=1.02]$. Planned comparisons among the means showed that more false negative errors were made in the absent condition than in either the replace or the permute condition $[F(1,14)=5.04, p=.04, F(1,14)$ $=5.67, p=.030$, respectively].

Two different analyses of position effects were performed for the positive and negative trials. As in Experiments $2-4$, negative targets varied with respect to the position of the sign character (first, middle, or last position). While no significant differences emerged in the RT analysis (mean RTs are 503, 506, and $508 \mathrm{msec}$ for the first, middle, and last positions, respectively; $F<1$ ), there was a main effect in the error data $[F(2,14)=$ $\left.10.49, M S_{\mathrm{e}}=.004, p<.01\right]$. More false positive errors were made when the sign character was placed in the last position $(7.1 \%)$ than in either the first $[3.2 \% ; F(1,14)=$ $7.51, p<.05]$ or the middle $[4.7 \% ; F(1,14)=20.7, p<$
$.01]$ position, thus confirming the effects observed in Experiment 4.

On positive trials, it was possible to examine how performance varied as a function of the position of letters that remained unchanged between prime and target (with the absent condition excluded). However, since this factor was not varied in the same way for the permute and replace priming conditions, separate analyses were performed for these two conditions. In the permute prime condition, an analysis with the position of the unchanged letter (first, second, or third letter) as a withinsubject factor showed no effect in the RT analysis $(F<1)$. Mean RTs for when the first, second, and third letter remained in the same position in the prime and target trigrams were 467, 470, and $469 \mathrm{msec}$, respectively. An analysis of the error data also showed no effect of this factor $(F<1)$. The subjects gave a false negative response on $2.1 \%, 2.3 \%$, and $2.5 \%$ of the trials when the first, second, and third letter remained unchanged. Thus, this replicates the results of Experiment 3 in showing an absence of position effects in a permute priming situation.

The replace priming condition was analyzed as a function of the position of the replaced letter. Although the main effect of this factor was not significant in the RT analysis $\left[F(2,14)=2.6, M S_{\mathrm{e}}=69.87, p=.11\right]$, the fastest RTs were obtained when the last letter was replaced ( $463 \mathrm{msec}$ ), and these were significantly faster than when the middle letter was replaced $[471 \mathrm{msec}$, $F(1,14)=4.76, p<.05]$. When the first letter was replaced (469 msec), RTs did not differ significantly from those obtained when either the last letter $[F(1,14)=$ $2.51]$ or the middle letter $(F<1)$ was replaced. In the error analysis, no significant effects were obtained $(F<1)$. Subjects made false negative responses on $2.7 \%$, $1.5 \%$, and $2.3 \%$ of trials with the first, the second, and the third letter replaced, respectively.

\section{Discussion}

The results of Experiment 5 demonstrate significant position-specific (replace condition) and positionindependent (permute condition) priming effects in conditions where subjects were apparently not using a perceptual match between prime and target to speed responding. Had they done so, we should have observed significantly more false positive errors to negative targets preceded by primes that had matching letters (e.g., FDR-FD\%). Although the magnitude of constituent

Table 6

Mean Reaction Times (RTs, in Milliseconds) and Mean Error Percentages Obtained in the Three Priming Conditions of Experiment 5 Tested on Both Positive and Negative Trials

\begin{tabular}{|c|c|c|c|c|c|c|c|c|c|}
\hline \multirow[b]{2}{*}{ Trial } & \multicolumn{3}{|c|}{ Replace } & \multicolumn{3}{|c|}{ Permute } & \multicolumn{3}{|c|}{ Absent } \\
\hline & RT & $S D$ & Error \% & RT & $S D$ & Error \% & RT & $S D$ & Error \% \\
\hline & 468 & 25.4 & 2.2 & 469 & 25.9 & 2.3 & 478 & 25.9 & 3.7 \\
\hline Negative & 506 & 27.8 & 5.9 & 506 & 26.8 & 3.8 & 506 & 33.1 & 5.3 \\
\hline
\end{tabular}


letter-priming effects is smaller in the binary decision variant of multiple alphabetic decision (compare the permute priming condition of Experiment 5 with the priming effects obtained in Experiment 3), the results of Experiments 2 and 3 did allow us to correctly predict similar-sized priming effects for the replace and permute conditions. This suggests some degree of compatibility between the priming effects obtained in the go/nogo situation and the binary decision task.

The fact that correct negative RTs were absolutely flat across the different priming conditions in Experiment 5 suggests that subjects were using a fixed temporal deadline in order to give a negative response in the multiple alphabetic decision task. In other words, a no response will be produced if a given state necessary for triggering a yes response has not been attained before a given time limit. This deadline will be set as low as possible (to give the fastest possible correct negative RTs) while maintaining an acceptable level of false negative errors. Within the particular theoretical framework to be developed in what follows, the priming effects observed on both positive RTs and false negative error rate result from the prime stimuli's preactivation of the letter representations that are involved in triggering a positive response. Such preactivation would allow letter representations to reach critical activation levels more rapidly, thereby allowing for faster positive responses and leaving less opportunity for erroneous negative responses. The general discussion section examines the type of letter representations that might possibly underlie these constituent letter-priming effects, and reflects on exactly how a positive response might be generated on the basis of such letter-level activity.

The position effects observed in Experiment 5 replicate those obtained in the previous experiments. On negative trials, significantly more false positive errors occurred when the sign character occupied the last position in the string. On positive trials, in the permute priming condition there was no effect of the position of the nonpermuted letter, as had also been observed in Experiment 3. However, in the replace priming condition, there was some evidence for position effects in the RT analysis, with the fastest latencies arising when the last letter in the target was replaced. In the general discussion, this pattern of position effects obtained in the multiple alphabetic decision task will be discussed in relation to a tentative description of how subjects might be performing the task.

\section{GENERAL DISCUSSION}

The present experiments have provided further evidence for the utility of the masked constituent letterpriming paradigm combined with the alphabetic decision task (Grainger \& Jacobs, 1991) as a tool for investigating position coding in letter strings. By manipulating the positions of letters shared by prime and target stimuli in each string (letters could have either the same position or a different position), it was possible to provide estimates of both position-specific and position-independent constituent letter-priming effects. These effects were measured relative to a control condition where prime stimuli did not contain any of the target letters. Positionspecific priming was always larger than positionindependent priming and was already present at $33-\mathrm{msec}$ prime exposures, while position-independent priming started to emerge only at $50-\mathrm{msec}$ prime exposures.

As noted in the introduction, the majority of models of visual word recognition that have been developed over the last 25 years propose that printed words are recognized via stored orthographic descriptions in memory. Thus, it is commonly assumed that visual word recognition requires preliminary information about individual letter identities and their position in the stimulus. According to this view of the word-recognition process, the individual letters of the word must be accurately coded for identity and position in the earliest phases of processing. The present results support such a view by showing that such identity and position information about individual letters can, indeed, be generated extremely rapidly. The question to be examined now is exactly how such position information is computed by the visual word-recognition system.

\section{Mechanisms for Coding Letter Position}

Perhaps the simplest method that could be used to code letter-in-string position would be to scan the letter string from beginning to end and to assign a rank to each identified letter (e.g., BALE coded as: $\mathrm{B}=1 \mathrm{st}, \mathrm{A}=2 \mathrm{nd}$, $\mathrm{L}=3 \mathrm{rd}, \mathrm{E}=4 \mathrm{th}$ ). This simple algorithm would provide a foolproof coding scheme for printed word recognition (assuming accurate letter recognition). One would simply have to search for the corresponding orthographic description in memory. However, this simple left-toright order of processing letters does not account for some typical effects usually obtained in word-recognition studies. Thus, for example, it has been frequently reported that, under tachistoscopic exposures, end letters enjoy an advantage over internal letters in letter-search tasks (Hammon \& Green, 1982; Mason, 1982), in barprobe tasks (Merikle, Lowe, \& Coltheart, 1971; Townsend, 1973), in full-report tasks (Lefton, Fisher, \& Kuhn, 1978; Wolford \& Hollingsworth, 1974), and in primed word recognition (Jordan, 1990). End-letter advantages cannot be explained by assuming that letters are processed consistently from the first to the last. Furthermore, as this effect is obtained with random-letter strings as well as with words, top-down mechanisms cannot be entirely responsible. The widely accepted interpretation of this phenomenon is that the first and last letters in a string suffer less lateral masking than do internal letters (e.g., Estes, 1972; but see Mason, 1982). One means of implementing such lateral masking effects will be discussed in what follows.

McClelland and Rumelhart (1981) proposed a model of letter-in-word perception (the interactive-activation model) in which letters within a string were processed in parallel by a set of specialized position-specific letter detectors (PSLDs). Each letter in a stimulus string is al- 
located to a channel in which information is analyzed for the presence of specific letter features. The outputs of feature detectors for a given channel serve as input to a bank of letter detectors for that channel. Thus, position information is automatically coded by the system, and a letter is always identified in its specific position within the string.

Indirect evidence in favor of the PSLD hypothesis embodied in the interactive-activation model comes from studies showing effects of positional letter frequency (spatial redundancy) on letter-in-string recognition. Thus, for example, Mason (1975) demonstrated that letter-search time in good readers was faster in letter strings with high average positional letter frequencies than in strings with low positional letter frequencies. This can be explained, within the interactive activation framework, in terms of higher levels of facilitatory feedback from word units to the PSLDs that correspond to letters with high positional letter frequencies. This follows directly from the fact that, by definition, a letter with a high positional frequency is shared by more words with higher printed frequencies (and therefore higher resting-level activation in the model) than is a letter with low positional frequency.

More direct evidence in favor of PSLDs comes from the positional component of the location-probability effect (i.e., target letters are detected more rapidly when they appear in locations that commonly contain a target than when they appear in locations that rarely contain a target). Miller (1988) successfully isolated the spatial and the positional components of the location-probability effect by occasionally shifting letter strings one character position to the left or to the right relative to their normal, centered mode of presentation. Significant facilitation was observed when displays contained the target letter either in the high-probability relative position or in the high-probability spatial location. This result suggests that information about the spatial location of a letter in the visual field as well as information about the relative position of a letter in a string are coded automatically. Furthermore, Miller found that the facilitative effect was largely identity specific. Two types of targets were used, an inducing target, which was displayed more often at a certain location, and a test target, which was displayed equally often at all locations. The facilitation obtained for the inducing target in the high-probability position was twice as large as the facilitation for the test target in the high-probability location. PSLDs nicely account for both the position-specific facilitation and the identityspecific facilitation obtained in the location-probability effect.

Another empirical result in favor of PSLDs was reported by Chastain (1977). In his experiment, subjects were presented with sets of trigrams that were repeatedly exposed for brief durations in random order. Once a letter of a trigram was recognized, the letters in the same spatial position in other trigrams could be recognized more rapidly if they possessed the same features as the letter originally perceived than if they did not. This result suggests the existence of extracting processes sensitive to common features and specific for a particular spatial position. Nevertheless, a strict version of the PSLD hypothesis, as implemented in the interactiveactivation model (McClelland \& Rumelhart, 1981), does have difficulty in accounting for a number of empirical findings to be discussed below.

\section{Position-Specific and Position-Independent \\ Letter Representations}

One result of the present experiments that the PSLD hypothesis cannot handle directly concerns the effects of position-independent priming observed in the present experiments. The interactive-activation model postulates independent processing channels for each letter position with no cross-activation possible between channels. In other words, the features present in the stimulus string are grouped into processing channels corresponding to different letters in the string, and each feature group influences the activation levels of letter units in the corresponding position only. However, there are two ways the PSLD hypothesis could be extended to accommodate the position-independent priming effects. One involves adding a set of higher level, position-independent alphabetic units that receive input from the PSLDs. The other involves relaxing the independent-channels aspect of the model by introducing some form of cross-talk between neighboring letter positions.

Within the perspective of the first type of extension, position-independent letter detectors (PILDs) can be considered as units in a mental alphabet (alphabetum) that could be used, for example, in the process of letter naming and the recognition and memorization of letter identities without reference to position. PSLD units, on the other hand, can be thought of as a specialized system specifically subserving the processing of printed strings of letters in the highly automatized process of visual word recognition. In order to explain position-independent priming effects within this framework, one can either assume that responses in the alphabetic decision task are based on activity in PILD units or that responses are based on activity in PSLD units that receive facilitatory feedback from PILD units. The fact that position-independent priming develops after position-specific priming in the present experiments suggests that the PILD units of the alphabetum are indeed higher level units receiving input from PSLDs. At the shortest prime exposures, only PSLD units would be sufficiently activated to influence subsequent target processing, whereas with longer prime exposures, there would be enough time for information to reach PILD units and generate position-independent priming effects.

This combination of a PSLD and a PILD system vaguely resembles the approach adopted by Mozer $(1987,1989)$, in which processing flows through a series of representational levels where position information is gradually lost. More precisely, the extension applies the distinction (used by Mozer, 1989, among others) be- 
tween types and tokens in letter-in-string perception. Thus, the PSLD system processes token information in that repetitions of the same letter in a string are distinguished in this system, whereas the PILD system processes type information and so ignores letter repetitions. The critical difference between this approach and the one adopted by Mozer $(1987,1989)$ is that both position and identity information are conjoined in early stages of processing (by the PSLD system) in the present approach, whereas, according to Mozer, identity and location information are bound only after extended attentiondriven processing. The addition of a PILD system to the interactive-activation framework allows the model to accommodate the detrimental effects of repeated letters observed in certain letter-recognition tasks (Bjork \& Murray, 1977; Egeth \& Santee, 1981; Santee \& Egeth, $1980)$ as well as the inhibitory effects of homogeneity reported by Mozer (1989). Since the PILD system is higher in the information-processing hierarchy than the PSLD system, it will be more resistant to low-level noise such as pattern masking. In this case, repeated instances of the same letter will not be recorded and identification accuracy will drop accordingly.

\section{A Tentative Model of Multiple Alphabetic Decision}

In what follows, we shall examine the type of information that subjects might be using in order to respond rapidly and accurately in the multiple alphabetic decision task. This analysis is based on the theoretical framework of PSLD and PILD units described above. Two possibilities will be considered here: (1) A positive response is triggered once three distinct PSLD units (all targets were composed of three letters) have reached a critical activation level, in which case RT is determined by the slowest unit. (2) A positive response is triggered once the summed activity in the PILD system has reached a critical level (see Grainger \& Jacobs, 1995, for a similar proposal with respect to the lexical decision task). The results of Experiment 5 immediately allow us to exclude the first proposal, since this clearly predicts slower RTs in the replace prime condition (e.g., FDRFDS) than in the permute prime condition (FSD-FDS). In the replace condition, the target letter $S$ receives no preactivation from the prime stimulus. This will therefore slow responding relative to the permute condition, where all target letters are receiving some degree of preactivation. The results of Experiment 5, however, show that these two conditions give almost equivalent RTs and error rates.

To understand how the second proposal can accommodate the results of the present experiments, consider the following example. Given the prime stimulus BHF, then, following prime presentation (with appropriate exposure durations), the state of activation of the PSLDs at each position will be as follows: In Position 1, B is active; in Position 2, $\mathrm{H}$ is active; in Position 3, $\mathrm{F}$ is active. In the PILD system, the units corresponding to $\mathrm{B}, \mathrm{H}$, and
F will all be equally active. Now, to clarify matters even further, let us assume (totally arbitrarily) that after processing the prime stimulus, any active PSLD unit has an activation value of 0.5 , with PILD units being activated to a lesser degree (0.4), since they lie further along the information-processing hierarchy. The total level of preactivation (and therefore subsequent facilitation) is represented by the sum of the activation values of all PSLD and PILD units that will be involved in processing the target trigram. These summed activation values following presentation of the prime stimulus BHF will be as follows for the different conditions tested in the present experiments (different target trigrams are given here to represent the different priming conditions): $\mathrm{BHF}=2.7$ (Experiment 2, same position); BFH $=1.7$ (Experiment 3 and also Experiment 5, permute condition); BHT $=1.8$ (Experiment 5, replace condition); $\mathrm{FBH}=$ 1.2 (Experiment 2, different position). As noted in the discussion sections of Experiments 3 and 5, this is precisely the order of effect sizes that was obtained.

With regard to this tentative model of the multiple alphabetic decision task, a brief word is necessary concerning the end-position bias observed in false positive error rate in the present study. If positive responses are being triggered by a criterion set on global activity in the PILD system, then this particular result suggests that initial letters provide more excitatory input to PILDs than do end letters. Thus, the negative target PK\% would produce higher levels of activity than either the target $\mathrm{P} \% \mathrm{M}$ or the target \% $\mathrm{KM}$, and therefore be more likely to trigger a false positive response. Therefore, according to this analysis, the replace primes in Experiment 5 that maintained initial letters (i.e., with the last letter replaced) should have produced the strongest priming effects. This is precisely the pattern that was obtained. Moreover, within this theoretical framework, the absence of a position effect on RTs to positive trials in Experiment 3 as well as in the permute condition of Experiment 5 is explained by the fact that all the letters contributed to the overall priming effect in this particular situation. Finally, since it is hypothesized that negative responses are triggered by a deadline mechanism, the model correctly accounts for the absence of position effects in correct negative RTs and false negative error rates, as observed in Experiment 5.

\section{Lateral Interactions Between PSLDs}

Performance in the multiple alphabetic decision task can therefore be accounted for by a decision mechanism based on activity in PILD units. Concerning performance in the single alphabetic decision task, however, it would appear more likely that subjects base their responses on activity in the appropriate PSLD unit. In this case, position-independent priming effects can be accounted for only by appealing to facilitatory feedback from PILDs to the corresponding PSLDs. This cannot, however, account for effects of degree of displacement of prime and target letters in the single alphabetic deci- 
sion task (see discussion in Experiment 1), since the prime string FGH should facilitate the recognition of the target letter F in the string XFX to the same extent as in the string XXF. The fact that facilitation effects tended to be larger with XFX targets than with XXF targets suggests that position coding is not $100 \%$ accurate, and that evidence that a given letter is present in a given position in a string is also taken as (albeit less strong) evidence that the same letter is present in a neighboring position. In other words, the independent-channels aspect of the PSLD system should be relaxed somewhat to allow for a certain amount of cross-channel leakage. Although the present data are far from conclusive on this point, we feel that this particular extension of the interactive-activation model offers an interesting solution to the general question of lateral interactions between letters in a string.

Thus, within the framework of the interactive-activation model, feature units processed in each channel could send activation on to PSLD nodes in adjacent channels as well as on to the corresponding PSLD node for a given channel. This cross-channel feature-to-letter activation will be smaller in magnitude than within-channel feature-to-letter activation. Moreover, the amount of cross-channel facilitation will depend on the proximity of the channels-the closer the channels, the greater the activation. This extension of the model correctly predicts (as do other interactive-channels models; e.g., Estes, 1972) that lateral interactions between letters in a string are a function of visual similarity, more similar letters creating the strongest interference (Estes, 1972; Krumhansl \& Thomas, 1977; McIntyre, Fox, \& Neale, 1970 ). This effect is explained in the present model by the fact that a visually similar adjacent letter will be sending cross-activation to an incorrect letter representation that will also be receiving strong within-channel activation due to feature overlap with the true letter. In the interactive-activation framework, letter representations within channels mutually inhibit each other (although this parameter is actually set to zero in the original model), since only one letter can possibly be present at a given location. In other words, this extension of the interactive-activation model of letter-in-string processing states that the inhibitory effects of adjacent letters are a result of within-channel letter-letter inhibition following cross-channel feature-letter facilitation. Of course, external letters suffer less inhibition than do internal letters, since they receive less cross-channel influence.

The verbal model of letter-in-string processing that has been developed here therefore incorporates two major extensions to the algorithmic model presented by McClelland and Rumelhart (1981), notably, the addition of position-independent letter representations and crosschannel leakage between PSLDs. These two extensions were incorporated to allow the model to capture the variation in the size of position-independent priming effects as a function of the degree of displacement of the critical letters in the prime and target strings of the present experiments. Since similar effects are also obtained in the multiletter matching task (Angiolillo-Bent \& Rips, 1982; Proctor \& Healy, 1985, 1987; Proctor et al., 1991; Ratcliff, 1981), the proposed extension of the PSLD hypothesis could usefully be invoked to explain these results. One could hypothesize that subjects are matching patterns of activity in either the PSLD or the PILD system, depending on whether or not they are required to take order information into account. Thus, in the orderirrelevant version of this task (subjects respond same when the two letter strings contain the same letters irrespective of position), subjects can compare patterns of activity in the PILD system, whereas in the orderrelevant version (subjects respond same only when both identity and position information match), they can use PSLD activity in order to make a decision. The similarity of two rearranged letter strings (e.g., BRT-RTB) will be increased by cross-channel activation in the PSLD system (as hypothesized above), and will therefore vary as a function of degree of displacement of the letters in the two strings to be matched. This therefore correctly predicts that different responses to rearranged pairs in the order-relevant task are faster and more accurate as the degree of displacement increases (i.e., as similarity decreases). On the other hand, the opposite effects of degree of displacement on same responses in the orderirrelevant task can be explained as a priming effect at the level of PSLDs that reinforces the activity of PILD units via feedforward excitation. Increased activity in PILD units will lead to a faster and more accurate match decision.

Moreover, since degree of displacement directly affects PSLD activity and only indirectly affects PILD activity, we are led to correctly predict that the effects of this factor are larger in the position-relevant task than in the position-irrelevant task (Proctor et al., 1991). Also, since PSLD units are hypothesized to be activated before PILD units, this interpretation also correctly predicts that different responses to rearranged pairs in the orderrelevant task are faster and more accurate than same responses to the same stimuli in the order-irrelevant task.

\section{Conclusions}

Only future experimentation in this area will allow us to provide a complete test of the proposed extensions within the interactive-activation framework. The crosschannel facilitation that was proposed at the feature-toletter level could also be usefully implemented at the level of letter-to-word processing. In other words, letter units that are activated at a given position in a letter string of a given length could send activation not only to all word units of the same length containing that letter at that specific position, but also to (1) word units of the same length that contain that letter in neighboring positions, and (2) word units of different lengths containing that letter at that specific position. This would allow the interactive-activation model to handle the effects of relative position priming observed by Humphreys et al. (1990) and discussed in our introduction. It seems likely, however, in view of the recent evidence in favor of fast 
phonological coding in visual word recognition (Ferrand \& Grainger, 1992, 1993, 1994; Perfetti \& Bell, 1991; Perfetti, Bell, \& Delaney, 1988), that position coding in pronounceable strings of letters will involve sublexical phonological units that regroup individual letters in the string. With respect to this point, it will be interesting, in future experimentation, to compare constituent letterpriming effects in pronounceable and unpronounceable nonword strings.

\section{REFERENCES}

Angiolillo-Bent, J. S., \& Rips, L. J. (1982). Order information in multiple-element comparison. Journal of Experimental Psychology. Human Perception \& Performance, 8, 392-406.

BJORK, E. L., \& MurRaY, J. T. (1977). On the nature of input channels in visual processing. Psychological Review, 84, 472-484.

BUTLER, B. E. (1981). Identification and localization in tachistoscopic recognition: The effects of data- and resource-limitations. Canadian Journal of Psychology, 35, 36-51.

Chambers, S. M. (1979). Letter and order information in lexical access. Journal of Verbal Learning \& Verbal Behavior, 18, 225-241

Chastain, G. (1977). Feature analysis and the growth of a percept. Journal of Experimental Psychology: Human Perception \& Performance, 3, 291-298.

EgETH, H. E., \& SANTEe, J. L. (1981). Conceptual and perceptual components of interletter inhibition. Journal of Experimental Psychology: Human Perception \& Performance, 7, 506-517.

EsTES, W. K. (1972). Interactions of signal and background variables in visual processing. Perception \& Psychophysics, 12, 278-286.

Estes, W. K., Allmeyer, D. H., \& Reder, S. M. (1976). Serial position functions for letter identification at brief and extended exposure durations. Perception \& Psychophysics, 19, 1-15.

Ferrand, L., \& Grainger, J. (1992). Phonology and orthography in visual word recognition: Evidence from masked nonword priming. Quarterly Journal of Experimental Psychology, 45A, 353-372.

FERRAND, L., \& GRAINGER, J. (1993). The time-course of orthographic and phonological code activation in the early phases of visual word recognition. Bulletin of the Psychonomic Society, 31, 119-122.

FERRAND, L., \& GRAINGER, J. (1994). Effects of orthography are independent of phonology in masked form priming. Quarterly Journal of Experimental Psychology, 47A, 365-382.

FoRSTER, K. J. (1976). Accessing the mental lexicon. In E. C. J. Walker \& R. G. Wales (Eds.), New approaches to language mechanisms (pp. 257-287). Amsterdam: North-Holland.

Forster, K. J., \& DAVIS, C. (1984). Repetition priming and frequency attenuation in lexical access. Journal of Experimental Psychology: Learning, Memory, \& Cognition, 10, 680-690.

GRAINGER, J., \& JACOBS, A. M. (1991). Masked constituent letter priming in an alphabetic decision task. European Journal of Cognitive Psychology, 3, 413-434.

Grainger, J., \& JacoBs, A. M. (1993). Masked partial-word priming in visual word recognition: Effects of positional letter frequency Journal of Experimental Psychology: Human Perception \& Performance, 19, 951-964.

Grainger, J., \& JACOBS, A. M. (1995). Orthographic processing in visual word recognition: A multiple read-out model. Manuscript submitted for publication.

Greenberg, S. N. (1988). Are letter codes always activated? Perception \& Psychophysics, 44, 331-338.

GREenberG, S. N., \& VELLUTino, F. R. (1988). Evidence for processing of constituent single and multiletter codes: Support for multilevel coding in word perception. Memory \& Cognition, 16, 54-63.

Grice, G. R., \& REED, J. M. (1992). What makes targets redundant? Perception \& Psychophysics, 51, 437-442.

Hammon, E. J., \& GReEN, D. W. (1982). Detecting targets in letter and in non-letter arrays. Canadian Journal of Psychology, 36, 67-82.

Humphreys G. W., EvetT, L. J., \& Quinlan, P. T. (1990). Ortho- graphic processing in visual word identification. Cognitive Psychology, 22, 517-560.

JACOBS, A. M., \& GRAINGER, J. (1991). Automatic letter priming in an alphabetic decision task. Perception \& Psychophysics, 49, 43-52. JoHnson, N. F. (1977). A pattern-unit model of word identification. In D. Laberge \& S. J. Samuels (Eds.), Basic processing in reading: Perception and comprehension (pp. 91-126). Hillsdale, NJ: Erlbaum.

JoRDAn, T. R. (1990). Presenting words without interior letters: Superiority over single letters and influence of postmask boundaries. Journal of Experimental Psychology: Human Perception \& Performance, 16, 893-909.

KRUEGer, L. E. (1978). A theory of perceptual matching. Psycholog ical Review, 85, 278-304.

KRUMhanSL, C. L., \& ThOMAs, E. A. (1977). Effects of level of confusability on reporting letters from briefly presented visual displays. Perception \& Psychophysics, 21, 269-279.

Lefton, L. A., Fisher, D. F., \& KuHN, D. M. (1978). Left-to-right processing of alphabetic material is independent of retinal location. Bulletin of the Psychonomic Society, 12, 171-174.

MASON, M. (1975). Reading ability and letter search time: Effects of orthographic structure defined by single-letter positional frequency. Journal of Experimental Psychology: General, 104, 146-166.

MASON, M. (1982). Recognition time for letters and nonletters: Effects of serial position, array size, and processing order. Journal of Experimental Psychology: Human Perception \& Performance, 8, 724-738.

MCClelland, J. L., \& RumelharT, D. E. (1981). An interactive activation model of context effects in letter perception: Part 1. An account of basic findings. Psychological Review, 88, 375-407.

McIntyre, C., Fox, R., \& Neale, J. (1970). Effects of noise similarity and redundancy on the information processed from brief visual displays. Perception \& Psychophysics, 7, 328-332.

Merikle, P. M., Lowe, D. G., \& Coltheart, M. (1971). Familiarity and method of report as determinants of tachistoscopic performance. Canadian Journal of Psychology, 25, 167-174.

Mewhort, D. J. K., CAMpbell, A. J., MarChetti, F. M., \& Campbell, J. I. E. (1981). Identification, localization, and "iconic memory": An evaluation of the bar-probe task. Memory \& Cognition, 9, 50-67.

MILLER, J. (1988). Components of the location probability effect in visual search tasks. Journal of Experimental Psychology: Human Perception \& Performance, 14, 453-471.

MORTON, J. (1969). Interaction of information in word recognition. Psychological Review, 76, 165-178.

MOZER, M. C. (1987). Early parallel processing in reading: A connectionist approach. In M. Coltheart (Ed.), Attention and performance XII: The psychology of reading (pp. 83-104). Hillsdale, NJ: Erlbaum.

Mozer, M. C. (1989). Types and tokens in visual letter perception. Journal of Experimental Psychology: Human Perception \& Performance, 15, 287-303.

PaAP, K. R., Newsome, S. L., McDonald, J. E., \& Schvaneveldt, R. W. (1982). An activation-verification model for letter and word recognition: The word superiority effect. Psychological Review, 89, 573-594.

Perfetti, C. A., \& Bell, L. (1991). Phonemic activation during the first $40 \mathrm{~ms}$ of word identification: Evidence from backward masking and priming. Journal of Memory \& Language, 30, 473-485.

Perfett1, C. A., Bell, L. C., \& Delaney, S. M. (1988). Automatic (prelexical) phonetic activation in silent reading: Evidence from backward masking. Journal of Memory \& Language, 27, 59-70.

Proctor, R. W., \& Healy, A. F. (1985). Order-relevant and orderirrelevant decision rules in multiletter matching. Journal of Experimental Psychology: Learning, Memory, \& Cognition, 11, 519-537.

Proctor, R. W., \& Healy, A. F. (1987). Task-specific serial position effects in comparisons of multiletter strings. Perception \& Psychophysics, 42, 180-194.

Proctor, R. W., Healy, A. F., \& Van Zandt, T. (1991). Samedifferent judgments of multiletter strings: Insensitivity to positional bias and spacing. Perception \& Psychophysics, 49, 62-72.

RATCLIFF, R. (1981). A theory of order relations in perceptual matching. Psychological Review, 88, 552-572. 
SANTEe, J. L., \& Egeth, H. E. (1980). Interference in letter identification: A test of feature-specific inhibition. Perception \& Psychophysics, 27, 321-330.

Segui, J., \& Grainger, J. (1990). Priming word recognition with orthographic neighbors: The effects of relative prime-target frequency. Journal of Experimental Psychology: Human Perception \& Performance, 16, 65-76.

Seidenberg, M. S., \& McClelland, J. L. (1989). A distributed developmental model of word recognition and naming. Psychological Review, 96, 523-568.

TowNSEND, V. M. (1973). Loss of spatial and identity information following a tachistoscopic exposure. Journal of Experimental Psychology, 98, 113-118.
WOlFord, G., \& Hollingsworth, S. (1974). Retinal location and string position as important variables in visual information processing. Perception \& Psychophysics, 16, 437-442.

\section{NOTE}

1. We thank Seth Greenberg for pointing out this potential confound in the primed multiple alphabetic decision task.

(Manuscript received October 21, 1993; revision accepted for publication February 14, 1995.) 